Wright State University

CORE Scholar

Physics Faculty Publications

Physics

$10-1-2002$

\title{
Thermoelectric Effect Spectroscopy of Deep Levels in Semi- Insulating GaN
}

\author{
U. V. Desnica \\ M. Pavlovic \\ Z-Q. Fang \\ David C. Look \\ Wright State University - Main Campus, david.look@wright.edu
}

Follow this and additional works at: https://corescholar.libraries.wright.edu/physics

Part of the Physics Commons

\section{Repository Citation}

Desnica, U. V., Pavlovic, M., Fang, Z., \& Look, D. C. (2002). Thermoelectric Effect Spectroscopy of Deep Levels in Semi-Insulating GaN. Journal of Applied Physics, 92 (7), 4126-4128.

https://corescholar.libraries.wright.edu/physics/149

This Article is brought to you for free and open access by the Physics at CORE Scholar. It has been accepted for inclusion in Physics Faculty Publications by an authorized administrator of CORE Scholar. For more information, please contact library-corescholar@wright.edu. 


\title{
Thermoelectric effect spectroscopy of deep levels in semi-insulating GaN
}

\author{
U. V. Desnica and M. Pavlovića) \\ Ruder Bošković Institute, Bijenička 54, P. O. Box 1016, 10000 Zagreb, Croatia
}

Z.-Q. Fang and D. C. Look

Semiconductor Research Center, Wright State University, Dayton, Ohio 45435

(Received 14 March 2002; accepted for publication 12 July 2002)

\begin{abstract}
The report of thermoelectric effect spectroscopy (TEES) applied on semi-insulating GaN was presented. The type of TEES setup, especially suitable for film-on-substrate samples, was devised. TEES enabled determination of sign of observed deep traps. Using TEES and thermally stimulated current spectroscopy measurements in combination with the simultaneous multiple peak analysis formalism all important trap parameters were determined. The shallowest identified electron and hole traps had activation energies $E_{c}-0.09 \mathrm{eV}$ and $E_{v}+0.167 \mathrm{eV}$, respectively. Results indicate that both these traps, oppositely charged are present in the studied material in relatively high concentrations causing the electrical compensation and high resistivity. (C) 2002 American Institute of Physics. [DOI: 10.1063/1.1504168]
\end{abstract}

Gallium nitride $(\mathrm{GaN})$ is one of the most promising III-V nitride semiconductors due to its unique electronic and optical properties. Commercial short wavelength light emitting diodes as well as laser diodes, field effect transistors, and ultraviolet detectors are being developed. ${ }^{1,2}$ For both electrical and optical devices, defects with deep levels can be very important, and thus must be understood. ${ }^{3}$ There are several reports ${ }^{4,5}$ on deep levels in conductive GaN, obtained by using deep level transient spectroscopy (DLTS). Although there are number of studies of semi-insulating (SI) $\mathrm{GaN}^{6-9}$ very little is known about deep centers in this material. Thermally stimulated current (TSC) spectroscopy is a useful method for characterization of high-resistivity samples and it has been applied extensively to SI GaAs. ${ }^{10-12}$ On the other hand, it has been employed only a few times for SI GaN..$^{9,13}$ In these articles, a variety of deep levels were reported. Huang et al. (Ref. 13) reported five main deep levels $(0.11$, $0.24,0.36,0.53$, and $0.62 \mathrm{eV}$ ), while Look et al. ${ }^{9}$ have found two shallow traps $(0.09$ and $0.17 \mathrm{eV})$ and at least one deeper trap at $130 \mathrm{~K}$. TSC cannot distinguish whether the observed levels are electron or hole traps.

In this article, deep levels in SI GaN, grown by molecular beam epitaxy (MBE) ${ }^{9}$ were studied using thermoelectric effect spectroscopy (TEES). In contrast to TSC, TEES can determine the sign of the traps, so it can distinguish whether the observed levels are electron or hole traps. It is of obvious importance for the more accurate assignation of defect microscopic origin as well as for better understanding of the compensation mechanism in highly resistive or SI GaN. In addition, TSC and low-temperature photoconductivity $\left(I_{\mathrm{PC}}\right)$ measurements were performed. The sample was a $6-\mu \mathrm{m}-$ thick SI GaN layer grown at $800^{\circ} \mathrm{C}$ on $c$-plane sapphire. TEES was developed ${ }^{14}$ and later successfully applied in SI GaAs. ${ }^{14-16}$ In TEES, the deep traps are filled by illumination with white light at $86 \mathrm{~K}$. The subsequent heating in the dark

${ }^{a)}$ Electronic mail: pavlovic@ rudjer.irb.hr at a constant rate causes the release of trapped carriers. In addition to the temperature ramp, a temperature gradient is established along the sample, inducing a drift of the liberated charge carriers to the electric contacts, producing the thermoelectric effect and therefore the current in the outer circuit. ${ }^{14}$ The sign of the current depends on the type of the dominant charge carriers at a particular temperature, thus enabling a distinction between electron and hole traps. A simplified experimental configuration for TEES measurements was used, in which the temperature gradient along the sample was produced by adding a thin plate of a thermal conductor (copper) under one half of the sample and a thermal insulator (teflon) of equal thickness under the other half. This simple configuration excludes the additional heater, used in the original setup,${ }^{14}$ eliminating its damaging impact on measurement quality. Thus, the resulting gradient proved sufficient to produce TEES currents $\left(I_{\text {TEES }}\right)$ of a few picoamperes, which are values comparable to the ones obtained in a standard TEES experiment. ${ }^{14}$ The TSC measurement was performed using a standard procedure, often used for SI GaAs characterization, and which is described in detail elsewhere. ${ }^{11,12}$ Figure 1 presents TEES and TSC spectra, obtained with different heating rates $(\beta=0.4,0.6$, or $0.8 \mathrm{~K} / \mathrm{s})$. Both the TEES and TSC intensities increase with an increase of $\beta$, accompanied by a shift of the peak maxima towards higher temperatures. The whole TSC signal is of the same sign, since the charge released from both trap types contributes to the TSC current. However, the analogous TEES signal-which reflects the difference between positive and negative charges-reveals that carriers giving rise to TSC peak A, (near $100 \mathrm{~K}$ ), are partly electrons and partly holes, while the majority of carriers related to the TSC signal at higher temperatures has a positive sign. Two arguments support the assignment of peak A to a composite peak, resulting from both positive and negative carriers: (i) the maximum of peak $\mathrm{A}$-at any $\beta$-does not occur at the same $T$ in TSC and TEES, as would have been expected if both of the "sub" peaks had had the same sign; ${ }^{17}$ and (ii) for lower $\beta$, the integral of the TEES 


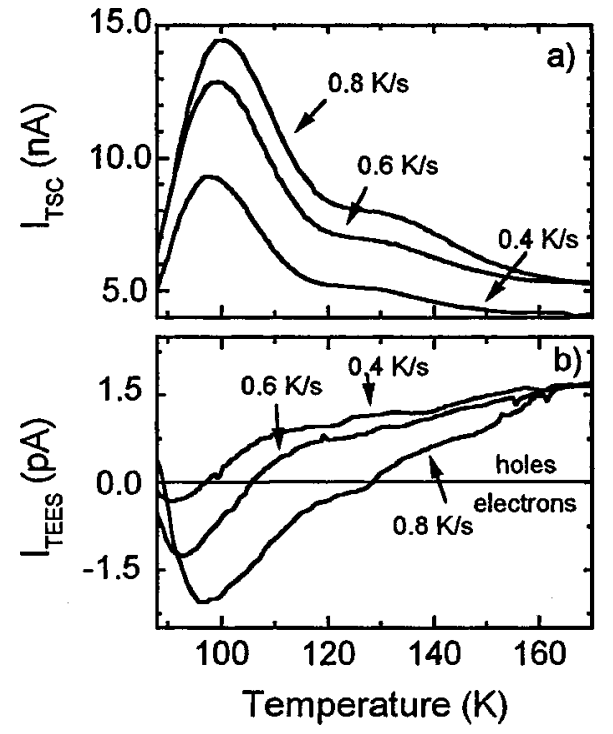

FIG. 1. (a) and (b) TSC and TEES curves, respectively, measured at heating rates $\beta=0.4,0.6$, and $0.8 \mathrm{~K} / \mathrm{s}$.

negative peak covers a narrower $T$ range, and the peak maximum is shifted towards lower $T$ in comparison to the maximum of A in the TSC spectra. This agrees with the notion that for lower $\beta$ the thermoelectric-effect driven separation of electrons and holes becomes less effective, giving rise to a more intense recombination of liberated electrons and holes.

Solely from the shape of TSC peak A, Look et al. ${ }^{9}$ concluded that $\mathrm{A}$ has to be a multicomponent peak and extracted activation energies $E_{A 1}=0.09 \pm 0.01 \mathrm{eV}$ and $E_{A 2}=0.17$ $\pm 0.05 \mathrm{eV}$ for two of its main components. In this article we have applied simultaneous multiple peak analysis (SIMPA) $)^{12,17}$ to the whole TSC spectrum to determine all components of peak A. As shown in Fig. 2, we have successfully fitted peak A with three deep traps $A_{1}, A_{2}$, and $A_{3}$.

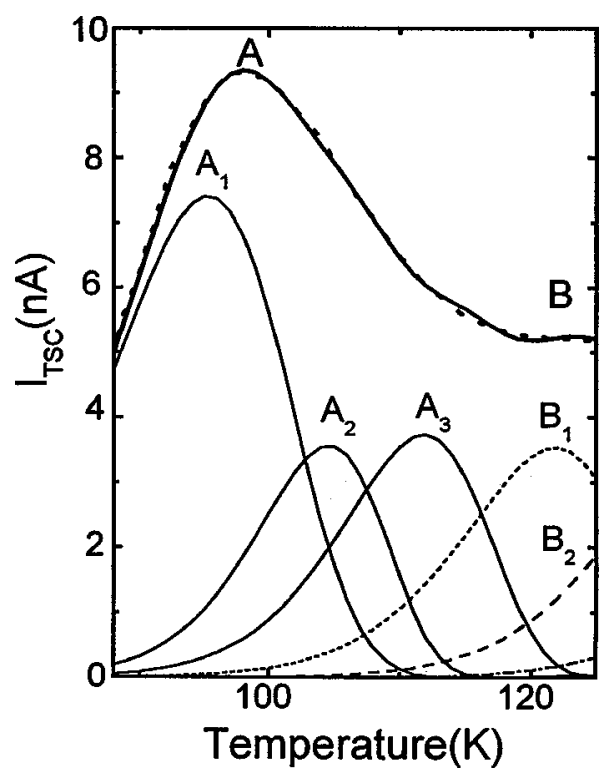

FIG. 2. SIMPA fit (thick solid curve) of the measured TSC spectrum (thick dotted curve). $A_{1}, A_{2}, A_{3}, B_{1}$, and $B_{2}$ are particular SIMPA peaks representing components of peaks $\mathrm{A}$ and $\mathrm{B}$, respectively.

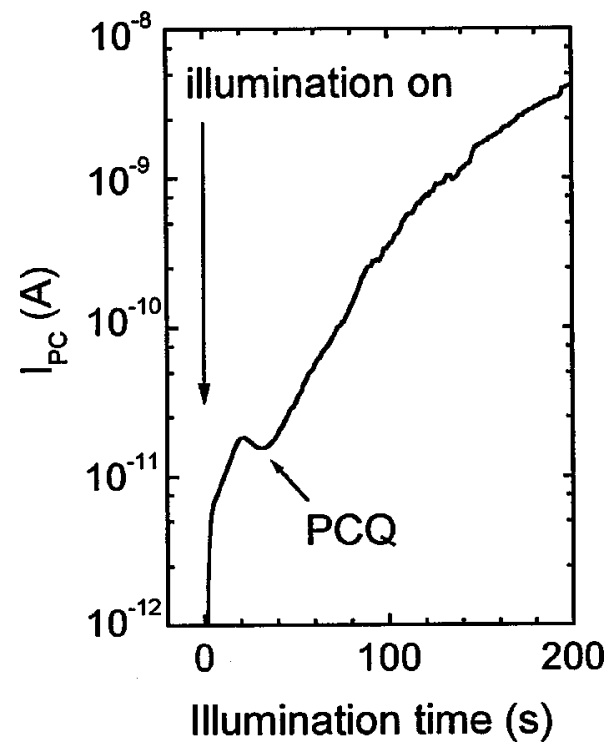

FIG. 3. Time evolution of photocurrent $\left(I_{\mathrm{PC}}\right)$ during white light illumination at $86 \mathrm{~K}$.

The sign of the TEES spectra indicates that $A_{1}$, the lowestenergy trap contributing to the A peak, is an electron trap, and the highest-energy trap, $A_{3}$, is a hole trap. As the TEES signal changes its sign just in the $T$ range corresponding to the $A_{2}$ trap, it is not possible to determine its sign with certainty. Namely, the activation energies of all three $A_{1}-A_{3}$ traps are relatively close, and the TEES signal from the $A_{2}$ trap might be overpowered either by electron trap $A_{1}$ or by hole trap $A_{3}$. The SIMPA analysis gives the following trap parameters: $E_{A 1}=E_{C}-(0.090 \pm 0.004) \mathrm{eV}, \sigma_{A 1}=(4.5 \pm 1.5)$ $\times 10^{-22} \mathrm{~cm}^{2}$, and $E_{A 3}=E_{V}+(0.167 \pm 0.008) \mathrm{eV}, \sigma_{A 3}=(5.0$ $\pm 1.5) \times 10^{-19} \mathrm{~cm}^{2}$. The value of $\sigma_{A 2}$ comes out either 9.4 $\times 10^{-19}$ or $6.7 \times 10^{-19} \mathrm{~cm}^{2}$, depending on whether $A_{2}$ is an electron or a hole trap. The product $N \tau \mu$, where $N$ is trap concentration, $\tau$ is a free-carrier lifetime, and $\mu$ is the carrier mobility, is $7.8 \times 10^{13}, 2.5 \times 10^{13}, 3.1 \times 10^{13} \mathrm{~cm}^{-1} \mathrm{~V}^{-1}$, for traps $A_{1}, A_{2}$, and $A_{3}$, respectively. This suggests high concentrations of all three traps, in the $10^{17} \mathrm{~cm}^{-3}$ range.

The temporal evolution of $I_{\mathrm{PC}}(t)$ during constantintensity white-light illumination at $86 \mathrm{~K}$ is presented in Fig. 3. $I_{\mathrm{PC}}$ shows clear photocurrent quenching (PCQ) in the early stage of the transient. Since photogeneration constantly supplies new $n$ and $p$, the observed decrease of $I_{\mathrm{PC}}(t)$ can be explained if there is a sudden switch between the dominant type of carrier in $I_{\mathrm{PC}}$ during illumination. Then considerable changes in $p$ and $n$ concentrations, their recombination rate and mobility would take place. Computer simulations have shown ${ }^{18}$ that such a switch —and the resulting PCQ - will occur in samples having "fast" and "slow" traps of opposite sign but comparable concentrations, due to preferential trapping of either electrons or holes during the early stages of illumination. An analogous quenching of $I_{\mathrm{PC}}$ was observed previously in SI GaAs during low- $T$ illumination ${ }^{14,19,20}$ in samples which also contained both electron and hole deep traps with quite different cross sections. ${ }^{14}$

Having now determined not only the energy but also the sign of the observed deep levels, the question of microscopic 
origin of donor level at $E_{c}-0.09 \mathrm{eV}$ and acceptor level at $E_{v}+0.167 \mathrm{eV}$, as well as the nature of the compensation mechanism can be analyzed with more plausibility. Based on the comparison of trap parameters, the most probable candidate for the electron trap $A_{1}$ is a defect related to the $\mathrm{N}$ vacancy. From the temperature-dependent Hall data, the thermal activation energy $\left(E_{T}\right)$ for the $\mathrm{N}$-vacancy donor, induced by electron irradiation (EI) has been determined ${ }^{21}$ to be 0.07 $\mathrm{eV}$. In addition, a broad, low-temperature DLTS peak $(E)$, induced by $1 \mathrm{MeV}$ EI, has an apparent activation energy of $0.18 \mathrm{eV}^{22}$ However, detailed DLTS fitting shows that (i) $E$ consists of ED1 and ED2; (ii) both centers have the same $E_{T}, 0.06 \mathrm{eV}$, which is very close to the $0.07 \mathrm{eV}$ found for the EI-induced N-vacancy donor; and (iii) both centers have different and small capture cross sections $\left(1-3 \times 10^{-20} \mathrm{~cm}^{2}\right.$ for $E D 1$ and $5-8 \times 10^{-19} \mathrm{~cm}^{2}$ for $\left.E D 2\right)$, with that of $E D 2$ being temperature dependent and having an activation energy $\left(E_{\sigma}\right)$ of $0.06 \mathrm{eV}^{23} \mathrm{We}$ speculate that the hole trap $\left(A_{3}\right)$ is due to the Ga vacancy, which is often the dominant acceptor in undoped $\mathrm{GaN}$, especially that grown by hydride vapor phase epitaxy, as confirmed by positron annihilation studies. ${ }^{24,25}$ According to theoretical calculations, ${ }^{26}$ (i) the $\mathrm{N}$ vacancy (a donor) has the lowest formation energy in $p$-type $\mathrm{GaN}$, and the Ga vacancy (an acceptor) in $n$-type GaN; and (ii) the isolated Ga vacancy in the negative charge state is triply occupied, with levels close to the valence band. There are many reports about deep levels related to impurity acceptors [such as Mg (Refs. 27 and 28)], however, so far there are no reports about any DLTS centers related to the Ga vacancy. It is possible that the TSC/TEES trap $A_{3}$ at $E_{v}+0.167 \mathrm{eV}$ is related to $\mathrm{Ga}$ vacancy. Since this activation energy is close to the reported activation energies for $\mathrm{Mg}$ (such as $136 \mathrm{meV}$ by admittance measurements, ${ }^{27} 135-155 \mathrm{meV}$ by Hall effect measurements, and $80-115 \mathrm{meV}$ by admittance measurements, ${ }^{28}$ respectively), we should not rule out the possibility that $A_{3}$ is due to $\mathrm{Mg}$, owing to possible contamination and memory effect during MBE growth. To clarify this issue, further TEES studies on high-resistive or semiinsulating GaN samples grown by other techniques are necessary.

The authors thank Dr. H. Morkoç for providing the MBE-grown SI-GaN. This research was supported by the
Ministry of Science and Technology of Croatia. Z-Q.F. and D.C.L. were supported under AFOSR Grant No. F49620-00$1-0347$.

${ }^{1}$ N. M. Johnson, A. V. Nurmikko, and S. P. DenBaars, Phys. Today 53, 31 (2000).

${ }^{2}$ M. A. Khan, Q. Chen, M. S. Shur, D. T. Dermott, J. A. Higgens, J. Burm, W. J. Shaff, and L. F. Eastman, IEEE Electron Device Lett. 17, 584 (1996).

${ }^{3}$ H. Morkoç, Mater. Sci. Eng., R. 33, 135 (2001).

${ }^{4}$ P. Hacke, T. Detchprohm, K. Hiramatsu, N. Sawaki, K. Tadatomo, and K. Miyake, J. Appl. Phys. 76, 304 (1994).

${ }^{5}$ W. Gotz, N. M. Johnson, R. A. Street, H. Amano, and I. Akasaki, Appl. Phys. Lett. 66, 1340 (1995).

${ }^{6}$ R. J. Molnar, T. Lei, and T. D. Moustakas, Appl. Phys. Lett. 62, 72 (1993).

${ }^{7}$ C. Wang and R. F. Davis, Appl. Phys. Lett. 63, 990 (1993).

${ }^{8}$ D. K. Gaskill, A. E. Wickenden, K. Doverspike, B. Tadayon, and L. B. Rowland, J. Electron. Mater. 24, 1525 (1995).

${ }^{9}$ D. C. Look, Z.-Q. Fang, W. Kim, Ö. Aktas, A. Botchkarev, A. Salvador, and H. Morkoç, Appl. Phys. Lett. 68, 3775 (1996).

${ }^{10}$ Z.-Q. Fang and D. C. Look, J. Appl. Phys. 69, 8177 (1991).

${ }^{11}$ U. V. Desnica and B. Santić, J. Appl. Phys. 67, 1408 (1990).

${ }^{12}$ M. Pavlović and U. V. Desnica, Jpn. J. Appl. Phys., Part 1 37, 4687 (1998).

${ }^{13}$ Z. C. Huang, J. C. Chen, and D. Wickenden, J. Cryst. Growth 170, 362 (1997).

${ }^{14}$ B. Šantić and U. V. Desnica, Appl. Phys. Lett. 56, 2636 (1990).

${ }^{15}$ Z. C. Huang, K. Xie, and C. R. Wie, Rev. Sci. Instrum. 62, 1951 (1991).

${ }^{16}$ K. Xie, Z. C. Huang, and C. R. Wie, J. Electron. Mater. 20, 553 (1991).

${ }^{17}$ M. Pavlović and U. V. Desnica, J. Appl. Phys. 84, 2018 (1998).

${ }^{18}$ U. V. Desnica, M. Pavlović, Z-Q. Fang, and D. C. Look (unpublished).

${ }^{19}$ J. Jimenez, M. A. Gonzales, J. A. deSaja, and J. Bonafe, J. Appl. Phys. 57, 1152 (1985); J. Jimenez, M. A. Gonzales, and L. F. Santacruz, Solid State Commun. 49, 917 (1984).

${ }^{20}$ W. C. Michel, D. W. Fischer, and M. O. Monasher, Solid State Commun. 71, 337 (1989).

${ }^{21}$ D. C. Look, D. C. Reynolds, J. W. Hemsky, J. R. Sizelove, R. L. Jones, and R. J. Molnar, Phys. Rev. Lett. 79, 2273 (1997).

${ }^{22}$ Z.-Q. Fang, J. W. Hemsky, D. C. Look, and M. Mack, Appl. Phys. Lett. 72, 448 (1998).

${ }^{23}$ L. Polenta, Z.-Q. Fang, and D. C. Look, Appl. Phys. Lett. 76, 2086 (2000).

${ }^{24}$ D. C. Look, C. E. Stutz, R. J. Molnar, K. Saarinen, and Z. Liliental-Weber, Solid State Commun. 117, 571 (2001).

${ }^{25}$ J. Oila, J. Kivioja, V. Ranki, K. Saarenen, D. C. Look, R. J. Molnar, and Y. Park, Mater. Res. Soc. Symp. Proc. (to be published).

${ }^{26}$ J. Neugebauer and G. Van de Walle, Phys. Rev. B 50, 8067 (1994).

${ }^{27}$ D. Seghier and H. P. Gislason, Physica B 273-274, 46 (1999).

${ }^{28}$ D. J. Kim, D. Y. Ryu, N. A. Bojarczuk, J. Karasinski, S. Guha, S. H. Lee, and J. H. Lee, J. Appl. Phys. 88, 2564 (2000). 